\title{
Design on Price Index Publishing System for Electronic Products
}

\author{
Jingzi Wang \\ Bohai University, Jinzhou, P.R. China \\ wangjingzi4032@sohu.com
}

Keywords: electronic products; price index; publishing system; functional design; detailed design

\begin{abstract}
With the rapid development of the Internet and the popularity of mobile devices, more and more people are accustomed to using a mobile device or computer online browsing information. In order to facilitate the people to understand the direction and extent of change in the price index of electronic products and start a study. First, the core functions of the system design through module structure diagram, and the each functional modules are described; then, lists the calculation formula of price index, the Laspeyres index and Paasche index formulas; Finally, using a flow chart for the detailed design of the main module, including the price index audit module and the price index browsing module. In this paper, the successful application of design results, can make the price index release process is simple and standardized, systematic, and improve the timeliness of the price index.
\end{abstract}

\section{Introduction}

Price index reflects the different periods of a group of goods (services item) changes in the direction of the price level, trends and extent of economic index, is a kind of economic index, usually the relative number between the reporting period and the base period contrast to represent. Price index is the study of price dynamics as a tool. Usual price index includes the consumer price index, the retail price index, prices index for fixed asset investment, stock price index, the price index of electronic products.

Electronic products price index, can be a timely response electronic products of electronic professional market (mainly include electronic components, mobile phone products, digital products, IT products such as the four categories [1]) price changes, the comprehensive response to electronic information products price state and development trends, will be in charge of industry and local government departments to accurately understand and grasp the operating status of electronic products, provide the basis for the electronic industry economic analysis and the development of relevant policies. Provide market information for electronic producers and operators, for market transactions, pricing strategy manufacturers, buyers formulate procurement budget to provide a reference, the production of marketable products, select and purchase timing of business products, to maintain a reasonable inventory, improve capital utilization rate; create conditions for market operators to improve the management level, improve the quality of service.

\section{System Core Functional Design}

Price index publishing system for electronic products to achieve core functions is shown in Fig. 1. A brief description of each function as follows: System maintenance management, the system administrator to manage the relevant information of systems, including user information management, user authorization management, system parameter setting, data backup and recovery; Basic information management, management the basic information of price index, including commodity classification information, product name information, the index category of information, base period product data information. Data acquisition management, collection of raw data needed to calculate the price index, the acquisition method can be screen input, it can be batch import, may also be a web search; Price index calculating management, calculated on the price index, which is calculated on the price index of mathematics formula implemented in the computer, the requirement of program has a strong reusability and versatility; Price index analysis management, using the way 
of chart analysis of the price index, can be in different periods of the same price index contrast, can also be in the same period of different price index contrast; Price index auditing management, and only after examination by the price index posted online, if not through, the publisher can be re-submitted for review after modification; Price index publishing management, the price index information posted online, only with a release privileges users can publish, can release a record every time, also can publish multiple records; Price index browsing management, used to query and browse detailed information of price index, the first enter the query conditions, using list approach to display all the records that satisfy the condition, click one of the records show detailed information.

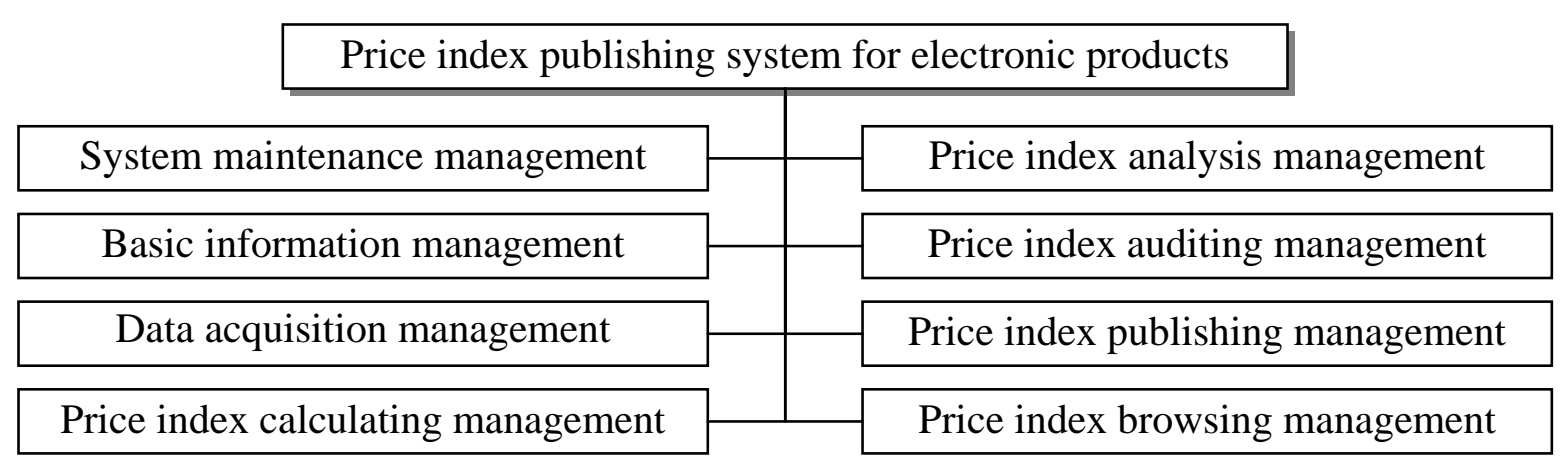

Fig. 1. System core function design

\section{Price Index calculating Formula}

From a historical perspective of the development of the index, the price index compilation method is mainly two: one is price index using the base period amount weighted calculation by German scholars E.Laspeyres proposed, referred to as Laspeyres index; the other is price index of weighted calculated using the reporting period, the number of German scholars P.Paasche proposed, referred to as the Paasche index.

If $p_{1 i}$ is the reporting period all selected $n(i=1,2, \cdots, n)$ commodities price, $p_{0 i}$ is these commodities price of base period, $q_{1 i}$ is the number of the reporting period sales of these commodities, $q_{0 i}$ is the number of the base period sales of these commodities.

The calculating formula of Laspeyres price index is [2]:

$$
P I_{L}=\sum_{i=1}^{n} p_{1 i} q_{0 i} / \sum_{i=1}^{n} p_{0 i} q_{0 i}, \quad i=1,2, \cdots, n
$$

The calculating formula for the corresponding Laspeyres quantity index is:

$$
Q I_{L}=\sum_{i=1}^{n} p_{0 i} q_{1 i} / \sum_{i=1}^{n} p_{0 i} q_{0 i}, \quad i=1,2, \cdots, n
$$

In the Laspeyres formula, whether it is price index and volume index, the use of weights are used during the report period the same metric weights.

If $k_{p i}=p_{1 i} / p_{0 i}$, the Laspeyres price index can be further expressed as:

$$
P I_{L}=\sum_{i=1}^{n} p_{1 i} q_{0 i} / \sum_{i=1}^{n} p_{0 i} q_{0 i}=\sum_{i=1}^{n} \frac{p_{1 i}}{p_{0 i}} p_{0 i} q_{0 i} / \sum_{i=1}^{n} p_{0 i} q_{0 i}=\sum_{i=1}^{n} k_{p i} p_{0 i} q_{0 i} / \sum_{i=1}^{n} p_{0 i} q_{0 i}
$$

If $k_{q i}=q_{1 i} / q_{0 i}$, the Laspeyres volume index can be further expressed as:

$$
Q I_{L}=\sum_{i=1}^{n} p_{0 i} q_{1 i} / \sum_{i=1}^{n} p_{0 i} q_{0 i}=\sum_{i=1}^{n} p_{0 i} q_{0 i} \frac{q_{1 i}}{q_{0 i}} / \sum_{i=1}^{n} p_{0 i} q_{0 i}=\sum_{i=1}^{n} k_{q i} p_{0 i} q_{0 i} / \sum_{i=1}^{n} p_{0 i} q_{0 i}
$$

The advantages of the Laspeyres index is used as the base period number as weights can eliminate the weight changes impact on the index, so that the price index of different periods comparable. But there are obvious shortcomings, under the assumption that sales unchanged, 
Changes in the price level of the reporting period, although can only reflect changes in the level of prices, but does not reflect the number of movements, especially not reflect changes in the number of structures.

The calculating formula of Paasche price index is [3, 4]:

$$
P I_{P}=\sum_{i=1}^{n} p_{1 i} q_{1 i} / \sum_{i=1}^{n} p_{0 i} q_{1 i}, \quad i=1,2, \cdots, n
$$

The calculating formula for the corresponding Paasche volume index is:

$$
Q I_{P}=\sum_{i=1}^{n} p_{1 i} q_{1 i} / \sum_{i=1}^{n} p_{1 i} q_{0 i}, \quad i=1,2, \cdots, n
$$

In the Paasche formula, whether it is price index and volume index, the use of weights are used during the base period the same metric weights.

If $k_{p i}=p_{1 i} / p_{0 i}$, the Paasche price index can be further expressed as:

$$
P I_{P}=\sum_{i=1}^{n} p_{1 i} q_{1 i} / \sum_{i=1}^{n} p_{0 i} q_{1 i}=\sum_{i=1}^{n} p_{1 i} q_{1 i} / \sum_{i=1}^{n} \frac{p_{0 i}}{p_{1 i}} p_{1 i} q_{1 i}=\sum_{i=1}^{n} p_{1 i} q_{1 i} / \sum_{i=1}^{n} \frac{1}{k_{p i}} p_{1 i} q_{1 i}
$$

If $k_{q i}=q_{1 i} / q_{0 i}$, the Paasche volume index can be further expressed as:

$$
Q I_{P}=\sum_{i=1}^{n} p_{1 i} q_{1 i} / \sum_{i=1}^{n} p_{1 i} q_{0 i}=\sum_{i=1}^{n} p_{1 i} q_{1 i} / \sum_{i=1}^{n} p_{1 i} q_{1 i} \frac{q_{0 i}}{q_{1 i}}=\sum_{i=1}^{n} p_{1 i} q_{1 i} / \sum_{i=1}^{n} p_{1 i} q_{1 i} \frac{1}{k_{q i}}
$$

The conventional practice in China index is that the comprehensive indexes of quantity use the quality index of the base period as a measure of the same factors; the comprehensive indexes of quality generally use the quantity index of report period as a measure of the same factors [5].

\section{Main Module Detailed Design}

This paper selects the flow chart for detailed design.

(1) The audit module of price index. Under the premise of the correctly verify the identity information, for the systems price index information is not audited and review. Module flow chart is shown in Fig. 2. The implementation process is: Show all price index unapproved list on the screen, select one of them for review. Modify audit property values in the database, if it passes, the audit attribute value "through"; if it do not pass, the audit attribute value "not through the audit ". An end after the audit, the audit can continue to audit, can also return.

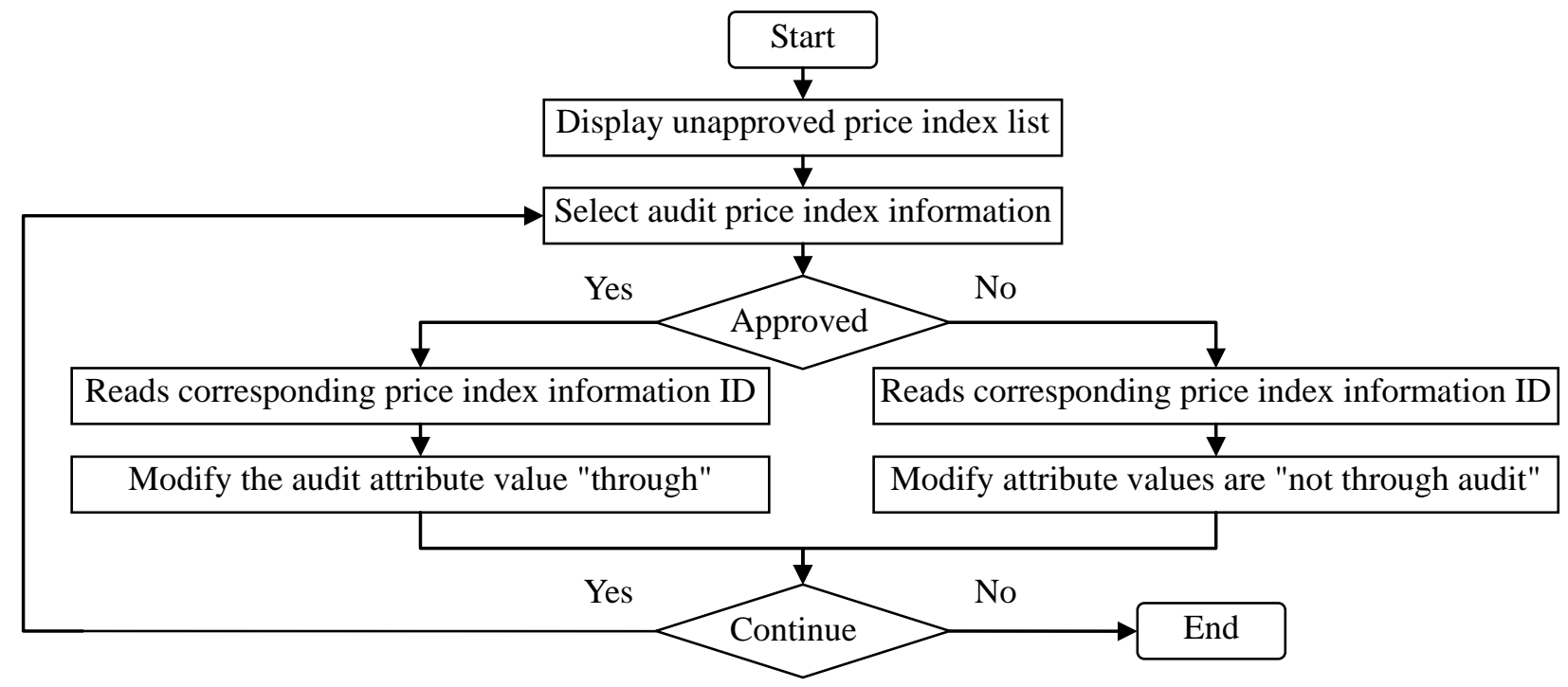

Fig. 2. Flow chart of price index auditing module

(2) Price index browsing module. The module is available to browsers important modules. Module flow chart is shown in Fig. 3. Implementation process are: browser input query condition, the program in the database query the data, to meet the conditions of the main information recorded 
shows in tabular form on the screen, the browser clicks a record to view the detailed information of the price index, each click can query a record and can also re-enter the query condition to retrieve.

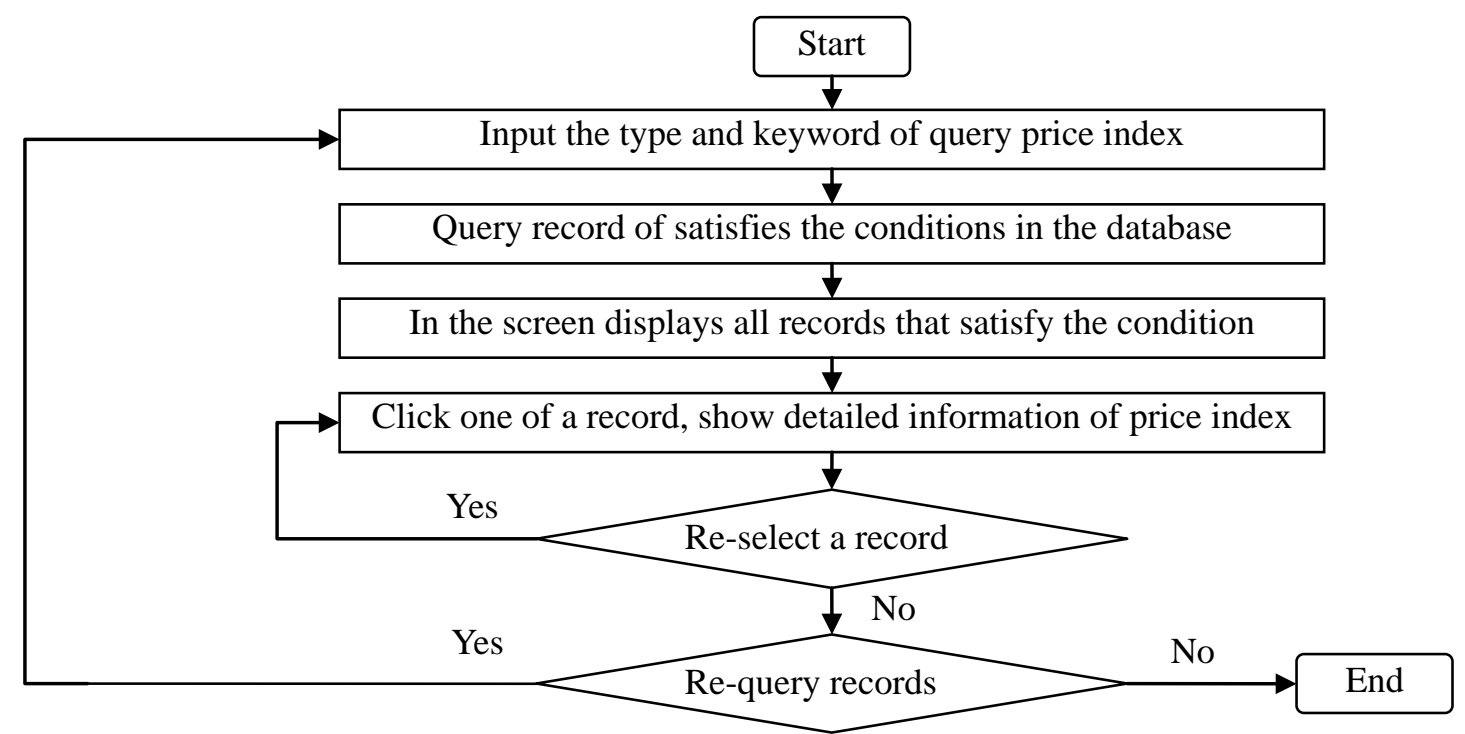

Fig. 3. Flow chart of price index browsing module

\section{Conclusion}

Can be integrated by the price index reflects changes direction and extent of changes in the overall phenomenon, analysis phenomenon in the overall change that the influence direction and extent in various factors, analysis the development trends of the social economic phenomenon in a long time, and for a comprehensive evaluation and determination of the social economic phenomena. With the development of information technology, faster and faster pace of life, people are more and more attention to the timeliness of the information. Traditional in newspapers, magazines media as the carrier cannot meet people's needs, based on the Web news publishing system will occupy the dominant position [6]. The successful application of this system, the publishing process of the price index can be simplified, standardized, and systematic, reduce unnecessary procedures, reduce the amount of waste of human and material resources, and improve the efficiency of the relevant departments.

\section{References}

[1] X. Y. He, "Huaqiang North electronic market price index steady extension," Price Theory \& Practice, vol. 31, no. 6, pp. 66-67, 2011.

[2] W. Zhang, C. L. Zhu, "Research on Theoretical Framework of CPI: Defects of and Remedies for Fixed Basket Price Index, " The Theory and Practice of Finance and Economics, vol. 35, no. 3, pp. 69-73, 2014.

[3] X. H. Huang, "Empirical Study and Construction of multi level CPI index, " China Business and Market, vol. 28, no. 9, pp. 52-58, 2014.

[4] Z. Y. Fan, J. Y. Song, "Does Consumer Price Index Reflect Changes in the Real Cost of Living of China, " Economic Theory and Business Management, vol. 34, no. 9, pp. 26-38, 2014.

[5] Douding network "Introduction and its calculation method for price index," http://www.docin.com/p-260498507.html, 2014-12-10.

[6] F. J. Ju, "Design and implementation on news publishing system based on Java Web," Information \& Communications, vol. 27, no. 7, pp. 97-98, 2013. 